\title{
THE USE OF HYPOTENSIVE DRUGS DURING ELECTRICAL ANAESTHESIA IN DOGS*
}

\author{
D. F. Cameron, M.D., AND J. W. R. MCInTyre, F.F.A.R.C.S.
}

DURING THE LAST FIFTY YEARS interest has been taken in the production of general anaesthesia by electrical current. In $1954 \mathrm{Knutson}^{1}$ described the use of a device consisting of an oscillator providing a sine wave signal of variable amplitude and frequency $20-20,000$ cycles/second to the amplifier, which was capable of producing currents up to $300 \mathrm{ma}$. through a load resistance of $200-300 \mathrm{ohms}$. An alternating current of 50-100 ma., 700 cycles/second, and approximately 15 volts was found to be most satisfactory for producing electrical anaesthesia in dogs, using this apparatus, but the technique had many disadvantages. One of the undesirable side-effects was hypertension. This finding was confirmed by McNeil, Turner, and Hardy² and by Hardy, Carter, and Turner ${ }^{3}$ using a modification of Knutson's apparatus, and in this department. Hardy and his. associates found a marked rise in circulating catecholamines and plasma steroids during the passage of the current, epinephrine being increased to a greater extent than $l$-Norepinephrine. Phentolamine prevented or abolished this rise in blood pressure. The use of phenoxybenzamine, trimethaphan, and reserpine in an attempt to abolish this hypertensive response is reported here.

Dogs were anaesthetized using thiopentone $20 \mathrm{mg} . / \mathrm{kg}$, atropine $0.1 \mathrm{mg} . / \mathrm{kg}$,, and an intravenous drip of 1.0 per cent succinylcholine. The animals were intubated and hyperventilated with room air using a mechanical ventilator. The electrodes were applied fronto-occipitally and the current used as recommended by Knutson. Blood pressure tracings were obtained from a cannulated femoral artery. The current was started at $35 \mathrm{ma}$., and, after the blood pressure had become stabilized, it was increased to $50 \mathrm{ma}$, and then by increments of $10 \mathrm{ma}$. to $100 \mathrm{ma}$. When the current had been cut off and the pressure had become stabilized at its normal level the phenoxybenzamine or trimetaphan was administered. Reserpine was given intraperitoneally 24 hours previously.' The current was then reapplied and arterial pressures recorded as before.

The results are given in Table I. One or more drugs were administered at weekly intervals to the same dog so that comparisons could be made. In the experiments with reserpine the control pressures for the same dog in other experiments were used. Trimetaphan was administered by intravenous drip and owing to technical difficulties encountered the dosage could not be calculated accurately. Its effectiveness in preventing a rise in pressure was limited, and in one animal who was rendered severely hypotensive the electric current was used to restore the pressure to near normal level. It appeared that phenoxybenzamine $5 \mathrm{mg}$. $/ \mathrm{kg}$. given intravenously was the most effective way of preventing the rise in blood pressure.

\footnotetext{
${ }^{\star}$ From the Departments of Pharmacology and Anaesthesia, University of Alberta, Edmonton,
} Alberta. 


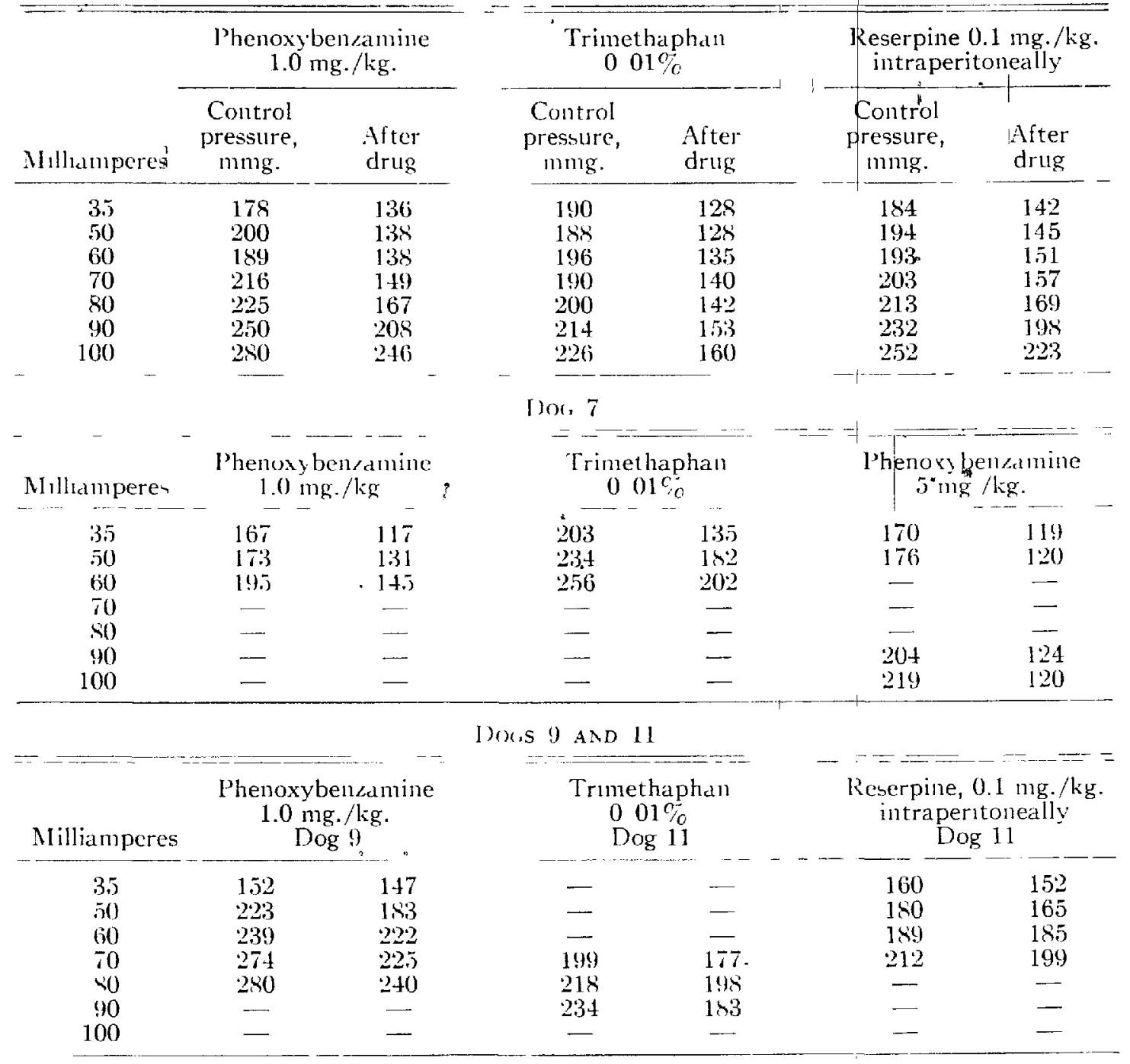

TABLE I

Dor 6

Dor 6 